\title{
Neuroprotective Effects of Pterois volitans Venom against Alcohol Induced Oxidative Dysfunction in Rats
}

Priyadharsini $\mathbf{S}^{1 *}$, Manoharan $\mathrm{J}^{2}$, Varadharajan $\mathrm{D}^{2}$ and Subramaniyan $\mathrm{A}^{1}$

${ }^{1}$ Department of Zoology, Annamalai University, Annamalai Nagar- 608 002, India

${ }^{2}$ Faculty of Marine Sciences, Centre of Advanced Study in Marine Biology, Annamalai University, Parangipettai- 608 502, Tamil Nadu, India

\begin{abstract}
The $P$. volitans generally is an edible fish, it protein are considered to be a source of food for human and the venom use for the development of new drugs. Pharmacological character of its venom were characterised during the study period. The lionfish venom shows the neuroprotective efficacy in alcohol intoxicated albino rat brain. These findings are further confirmed by histopathological observations. Therefore, the lionfish venom could be used as a neuroprotective agent.
\end{abstract}

Keywords: P. volitans; Venomous sting; Neuroprotective efficacy; Histopathology

\section{Introduction}

In the industrial world people are having some kind of problem which may be largely man-made and iatrogenic in origin. Still, we ignore and dismiss their growing incidence to factors which we assume are not preventable. Alcohol abuse is one of the major problems in Indian continent and is responsible for a significant percentage of hospital admission. Ethanol molecule is small and soluble in both water and lipids. It permeates all tissues of the body and affects most vital functions of virtually all organs including brain, liver, kidney, heart and pancreas [1]. Metabolism of alcohol leads to the generation of free radicals and the chain reaction of lipid peroxidation that causes damage to the brain and other vital organs. Therefore inhibition of free radical generation is important in providing protection against hepatic damage. Toxicity due to the alcohol consumption in the body leads to the changes in the main organs, especially the brain. The morbidity and mortality rate of heavy alcohol drinkers have since been reported to have reached $6.1 \%$ [2]. Alcoholic liver disease (ALD) is one of the most serious results of chronic alcohol abuse in the world $[3,4]$ have reported that the factors that mediate the occurrence of ALD are acetaldehyde, oxidative stress, hypoxia, immune response and membrane alterations. Antioxidants play a significant role in protecting living organism from the toxic effect of various chemicals by preventing free radical formation [5]. Now a days, alcohol produces various dysfunctions in the human being. A number of fish has venomous sting, including the family Scorpaenidae. Venomous species are only a few [6], as people consider it for edible. Due to venom extracts storing have some technical difficulties [7], the source of marine organisms especially fish, remain a largely unused source of novel compounds. The piscine venoms are effective on the cardiovascular systems and mostly all the piscine venoms produce profound cardiovascular changes. Generally, the piscine venom has different components even though the similarities exist between the responses to the venoms of all species of fish. Numerous fish venom has been examined for activity in rats. The oxidative stress is involved in many diseases and reactive oxygen species can be useful for immune system which might cure diseases. Therefore, these species still represent sources of pharmacological compounds that may be useful as research tools or lead compounds for drugs, and as such, their pharmacological actions have been the focus of recent work $[8,9]$. Venom is delivered when the spine pierces the tissue of the victim, the integumentary sheath enclosing the spine and venom is ruptured, and the venom enters the wound $[10,11]$. Marine toxins represent a vast source of novel pharmacological compounds that may prove useful either as research tools or therapeutic agents [12]. The venom of the greater Weever fish Trachinus draco contains high concentrations of both histamine and catecholamine's, and possesses cholinesterase activity [13]. The venom of the stingray Urobatix halleri contains 5-hydroxytryptamine (5-HT), 5-nucleotidase and phosphodiesterase [14]. The venom of all three species of stonefish Synanceia trachynis, $S$. horrida and S. verrucosa contain catecholamines [15], as well as a variety of enzymatic activities [16]. In addition, the venoms of the stonefish $S$. trachynis, the lionfish $P$. volitans and the freshwater stingray Potamotrygon motoro are believed to contain either acetylcholine or a cholinomimetic $[9,17]$. Hence, in the present study, attempts to evaluate the toxicity of lionfish $P$. volitans administered to rats and the incidence of oxidative stress and neurotoxicity are made.

\section{Materials and Methods}

Specimens of P. volitans (Figure 1) were obtained from the local aquarium, killed (by cooling), and the venomous spines were removed and stored in $10 \%$ glycerol solution at $-80^{\circ} \mathrm{C}$. The spines were thawed and ground in a chilled mortar and pestle in $10 \%$ glycerol solution. The suspension was then centrifuged (7000 g, 10 mins) the supernatant removed, the pellet resuspended again in approximately $1 \mathrm{ml}$ of $10 \%$ glycerol and recentrifuged. The final supernatants were pooled, assayed for protein concentration using a Bio-Rad Dc protein assay kit, and adjusted to a concentration of $1 \mathrm{mg} / \mathrm{ml}$ protein, before being aliquoted and stored at $-20^{\circ} \mathrm{C}$ until use and the venom was prepared as described by [11]. The protein was estimated by [18]. The concentration was adjusted to $1 \mathrm{mg} / \mathrm{ml}$; aliquoted and stored at $-20^{\circ} \mathrm{C}$ until use.

*Corresponding author: Priyadharsini S, Department of Zoology, Annamalai University, Annamalai Nagar- 608 002, Tamilnadu, India, Tel: 91-4144-238-796; Email: priyamano.zoo@gmail.com

Received November 01, 2014; Accepted June 16, 2015; Published June 21, 2015

Citation: Priyadharsini S, Manoharan J, Varadharajan D, Subramaniyan A (2015) Neuroprotective Effects of Pterois volitans Venom against Alcohol Induced Oxidative Dysfunction in Rats. J Environ Anal Toxicol 5: 306. doi:10.4172/2161 0525.1000306

Copyright: $(2015$ Priyadharsini S, et al. This is an open-access article distributed under the terms of the Creative Commons Attribution License, which permits unrestricted use, distribution, and reproduction in any medium, provided the original author and source are credited. 
Citation: Priyadharsini S, Manoharan J, Varadharajan D, Subramaniyan A (2015) Neuroprotective Effects of Pterois volitans Venom against Alcohol Induced Oxidative Dysfunction in Rats. J Environ Anal Toxicol 5: 306. doi:10.4172/2161-0525.1000306

Page 2 of 5

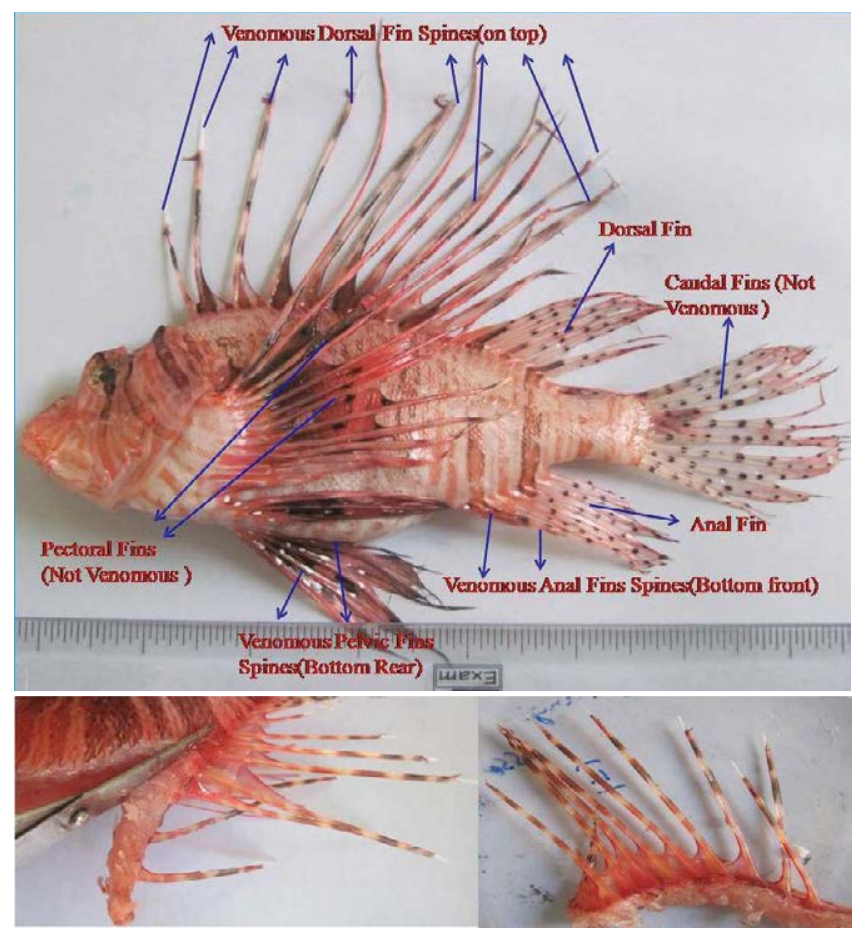

Figure 1: The lionfish $P$. volitans sting morphology fin locator.

\section{Stabilization of the venom}

The venom preparation was maintained at various temperatures for 1 hour $\left(-80^{\circ} \mathrm{C},-20^{\circ} \mathrm{C}, 0^{\circ} \mathrm{C}, 4^{\circ} \mathrm{C}, 37^{\circ} \mathrm{C}\right.$ and $\left.100^{\circ} \mathrm{C}\right)$ immediately brought back to room temperature and assayed for activity using rat bio assay. The venom preparation was kept at optimum temperature in different buffers namely $50 \mathrm{mM}$ acetate buffer with $\mathrm{pH}$ ranging from 3 to 6.2 and $50 \mathrm{mM}$ tris- $\mathrm{Hcl}$ buffer with $\mathrm{pH}$ ranging from $7-10$. The optimum $\mathrm{pH}$ was determined by performing the rat bioassay. The venom was stored at $-20^{\circ} \mathrm{C}$ in the presence of sodium aside for six months. Aliquots were withdrawn at every month and their activity was determined by rat lethality assay.

The experiments were carried out in adult male Wistar rats (180-200 g) procured from Central Animal House (CAH), Faculty of Medicine, Annamalai University. The animals were housed under the conditions of constant temperature $\left(24 \pm 2^{\circ} \mathrm{C}\right)$ and humidity (50-60\%), under a $12 \mathrm{~h}$ light $/ 12 \mathrm{~h}$ dark photoperiod in the $\mathrm{CAH}$ of the University. Water and standard laboratory food (Hindustan Lever Ltd., Mumbai, India) were provided ad libitum. The experimental protocol used in this study was approved (Reg. No.450/2007/CPCSEA) by the Institutional Animal Ethical Committee (IAEC) for the purpose of control and supervision on experimental animals of Rajah Muthiah Medical College, Annamalai University, Annamalainagar, India. After acclimatization, the animals were divided into 6 groups, consisting of 6 rats in each group (Figure 2).

\section{Experimental protocol}

Group 1: Control rats received normal saline $100 \mu \mathrm{l}$ orally for four weeks.

Group 2: Rats orally received with $20 \%$ alcohol in saline for four weeks.

Group 3: Rats orally received the $20 \%$ alcohol with $1 \%$ of $\mathrm{LD}_{50}$ dose $(42.5 \mu \mathrm{g} / \mathrm{kg})$ of venom in $100 \mu \mathrm{l}$ of sterile saline $(0.425 \mathrm{lg} / \mathrm{kg}$ BW by ip-low dose: $\mathrm{LD}_{50}$ ) for four weeks.

Group 4: Rats orally received the $20 \%$ alcohol with $1 \%$ of $\mathrm{LD}_{50}$ dose $(42.5 \mu \mathrm{g} / \mathrm{kg})$ of venom in $100 \mu \mathrm{l}$ of sterile saline $(2.125 \mathrm{lg} / \mathrm{kg}$ BW by ip-medium dose: MD) for four weeks.

Group 5: Rats orally received the $20 \%$ alcohol with $1 \%$ of $\mathrm{LD}_{50}$ dose $(42.5 \mu \mathrm{g} / \mathrm{kg})$ of venom in $100 \mu \mathrm{l}$ of sterile saline $(4.25 \mathrm{lg} / \mathrm{kg}$ BW by iphigh dose: HD) for four weeks.

Group 6: Rats received the $(2.125 \mathrm{lg} / \mathrm{kg}$ BW by ip-medium dose: MD) for four weeks.

The animals were maintained in their respective groups for four weeks. Food and fluid intake and body weights were measured weekly. At the end of the experimental period, the animals were anesthetized using ether and sacrificed by cervical decapitation. Brain tissues were excised, washed and homogenized in $0.1 \mathrm{M}$ Tris-HCl-0.001M EDTA buffer ( $\mathrm{pH} 7.4$ ) and centrifuged at $12,000 \mathrm{rpm}$ for $30 \mathrm{~min}$ at $4^{\circ} \mathrm{C}$. The supernatant was collected and used for the experiments. Brain tissue (250 mg) was sliced into pieces and homogenised in appropriate buffer in cold condition ( $\mathrm{pH} 7.0$ ) to give $20 \%$ homogenate (w/v). The homogenate were centrifuged at $1000 \mathrm{rpm}$ for $10 \mathrm{~min}$ at $0^{\circ} \mathrm{C}$ in cold centrifuge. The supernatant was separated and used for the assay of various biochemical estimations $[8,19]$.

\section{Determination of acetyl cholinesterase activity}

Acetyl cholinesterase (AChE) activity was determined in brain using acetylcholine iodide as a substrate according to the method of [20]. In this method AChE in samples hydrolyzes acetyl thiocholine iodide into thiocholine and butyric acid. The thiocholine reacts with 5,5'-dithiobis-2-nitrobenzoic acid to form 5-thio-2-nitrobenzoic acid. The yellow colour intensity is measured spectrophotometrically at $412 \mathrm{~nm}$ (Elico-SL177, Elico LTD. Hyderabad, Andhra Pradesh, India).

\section{Estimation of TBARS content}

The concentration of thiobarbituric acid reactive substances (TBARS) were estimated in brain by the method of [21] using 1,1',3,3'-tetramethoxypropane as the standard.

\section{Determination of non-enzymatic antioxidants}

The levels of reduced glutathione (GSH) in brain homogenate were

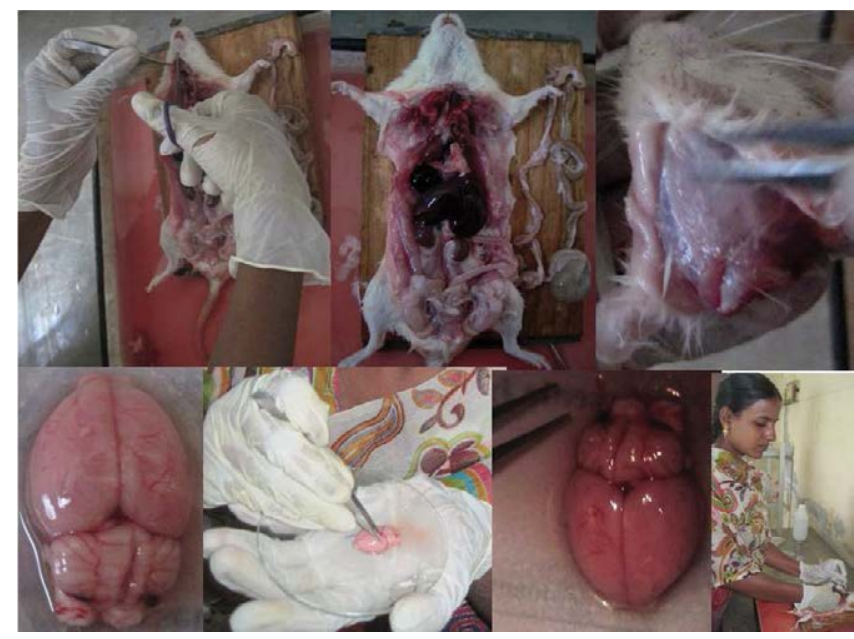

Figure 2: Dissection and whole mount of brain tissue in Wister rats. 
Citation: Priyadharsini S, Manoharan J, Varadharajan D, Subramaniyan A (2015) Neuroprotective Effects of Pterois volitans Venom against Alcohol Induced Oxidative Dysfunction in Rats. J Environ Anal Toxicol 5: 306. doi:10.4172/2161-0525.1000306

determined by the method of [22], based on the reaction with Ellman's reagent ( $19.8 \mathrm{mg}$ DTNB in $100 \mathrm{ml}$ of $0.1 \%$ sodium citrate). The levels of total sulphydryl groups (TSH) were measured after the reaction with 5,5'-dithiobis-2-nitrobenzoic acid using the method of [23].

\section{Determination of enzymatic antioxidants}

Superoxide dismutase (SOD) activity in the brain was assayed by the method of [24] based on the inhibition of formation of NADHphenazine methosulphate-nitrobluetetrazolium complex. One unit of SOD corresponds to the amount of enzyme causing $50 \%$ reduction of nitro blue tetrazolium $/ \mathrm{min} / \mathrm{mg}$ of protein. Catalase (CAT) was assayed by the method of [25] by quantitating the $\mathrm{H}_{2} \mathrm{O}_{2}$ consumed after the enzymatic reaction. Dichromate in acetic acid was used as the coloring agent. The activity of catalase is expressed as $\mu$ moles $\mathrm{H}_{2} \mathrm{O}_{2}$ consumed/ $\mathrm{min} / \mathrm{mg}$ of protein. GPx activity was assayed in brain by the method of [26].

\section{Processing of tissues for histopathological studies}

One half of brain was fixed in $10 \%$ formalin solution. The fixed tissues were processed, embedded in paraffin and sectioned (5-6 $\mu)$. The sections were stained with hematoxylin and eosin (H and E) and observed under microscope. The brain sections were examined for gliosis, pycnosis, spongiosis, inflammatory infiltrate, oedema and meningeal changes.

\section{Statistical analysis}

Values are given as the mean \pm S.D. Significant difference between the means of the six groups was statistically analyzed by Duncan's Multiple Range Test (DMRT). The significance levels was set at $\mathrm{P}<0.05$ for all the tests. Statistical analysis was performed using SPSS 11.0 software package (SPSS, Chicago, IL, USA).

\section{Results}

The bioassay test shows that the venom was more stable and active at the optimum temperature of at $37^{\circ} \mathrm{C}$ and the bioassay test shows that the venom was more stable and active at the optimum $\mathrm{pH}$ of at 7-8.

\section{Brain AChE}

The activity of AChE in brain of control and experimented rats are shown in Figure 3. The activities of AChE in brain was significantly $(\mathrm{P}<0.05)$ decreased in alcohol treated rats when compared with control rats whereas the administration of venom in alcohol intoxicated rats

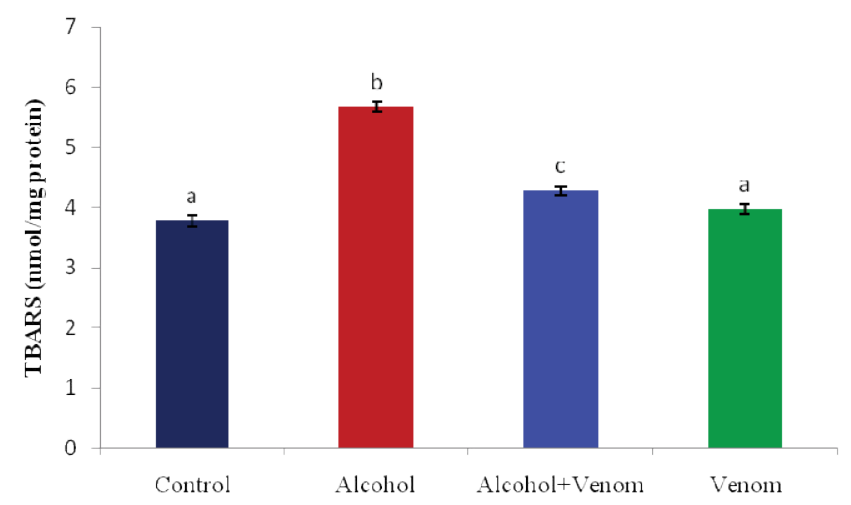

Figure 3: Effects of venom on the levels of TBARS in the brain of control and experimental rats. significantly $(\mathrm{P}<0.05)$ increased the activities of $\mathrm{AChE}$ to near normal levels when compared with alcohol treated rats.

\section{Oxidative stress marker in brain}

The data presented in Figure 4 shows the changes in the levels of brain lipid peroxidation indices thiobarbituric acid reactive substances (TBARS). The rats treated with alcohol, the levels of brain TBARS was increased $(\mathrm{P}<0.05)$ significantly when compared with control rats. Administration of venom in alcohol intoxicated rats significantly $(\mathrm{P}<0.05)$ decreased the level of these oxidative stress marker in brain when compared with alcohol treated rats.

\section{Non-enzymatic antioxidants in brain}

The level of non-enzymatic antioxidants (GSH and TSH) in the brain of control and experimental rats were shown in Table 1. The levels of GSH and TSH were significantly $(\mathrm{P}<0.05)$ decreased in the brain tissues of alcohol intoxicated rats, when compared to control rats. Administration of venom in alcohol treated rats significantly $(\mathrm{P}<0.05)$ depleted the levels of GSH and TSH contents in brain when compared with alcohol treated rats.

\section{Enzymatic antioxidants brain}

The activities of enzymatic antioxidants (SOD, CAT and GPx)

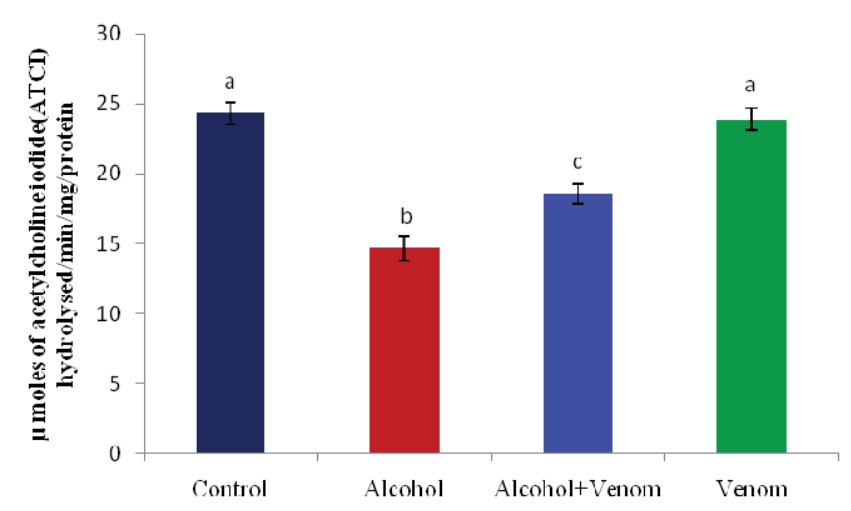

Figure 4: Effects of venom on the levels of AChE in the brain of contro and experimental rats.

\begin{tabular}{|l|c|c|c|c|}
\hline Groups & Control & Alcohol & Alcohol+Venom & Venom \\
\hline GSH $(\mu \mathrm{g} / \mathrm{mg}$ protein) & $4.02 \pm 0.9^{\mathrm{a}}$ & $2.13 \pm 0.12^{\mathrm{b}}$ & $3.04 \pm 0.16^{\mathrm{c}}$ & $4.06 \pm 0.05^{\mathrm{a}}$ \\
\hline TSH $(\mu \mathrm{g} / \mathrm{mg}$ protein $)$ & $48.12 \pm 0.24^{\mathrm{a}}$ & $28.24 \pm 0.28^{\mathrm{b}}$ & $98 \pm 0.78^{\mathrm{c}}$ & $51 \pm 0.89^{\mathrm{d}}$ \\
\hline
\end{tabular}

Values are mean \pm SD for 6 rats in each group; a, b, c and Values are not sharing a common superscript letter (a, b, c and d) differ significantly at $p<0.05$ (DMRT). The levels of GSH and TSH were expressed as $\mu \mathrm{g} / \mathrm{mg}$ protein.

Table 1: Effects of venom on the levels of GSH, TSH, the brain of control and experimental rats.

\begin{tabular}{|l|c|c|c|c|}
\hline Groups & Control & Alcohol & Alcohol+Venom & Venom \\
\hline SOD (min/mg protein) & $22.08 \pm 0.42^{\mathrm{a}}$ & $15.22 \pm 0.28^{\mathrm{b}}$ & $18.98 \pm 0.47^{\mathrm{c}}$ & $21.64 \pm 0.54^{\mathrm{a}}$ \\
\hline CAT (min/mg protein) & $8.13 \pm 0.43^{\mathrm{a}}$ & $3.17 \pm 0.22^{\mathrm{b}}$ & $4.83 \pm 0.36^{\mathrm{c}}$ & $7.88 \pm 0.31^{\mathrm{a}}$ \\
\hline GPx (min/mg protein) & $6.24 \pm 0.54^{\mathrm{a}}$ & $3.67 \pm 0.43^{\mathrm{b}}$ & $4.48 \pm 0.62^{\mathrm{c}}$ & $5.98 \pm 0.48^{\mathrm{a}}$ \\
\hline
\end{tabular}

Values are mean \pm SD for 6 rats in each group; ${ }^{a, b, c}$ and Values are not sharing a common superscript letter ( $a, b, c$ and d) differ significantly at $\mathrm{P}<0.05$ (DMRT). SOD - One unit of enzyme activity was taken as the enzyme reaction, which gave $50 \%$ inhibition of NBT reduction in one minute/mg protein.

CAT $-\mu \mathrm{mol}$ of $\mathrm{H}_{2} \mathrm{O}_{2}$ utilized $/ \mathrm{min} / \mathrm{mg}$ protein.

$\mathrm{GPx}-\mu \mathrm{g}$ of $\mathrm{GSH}$ consumed $/ \mathrm{min} / \mathrm{mg}$ protein.

Table 2: Effects of venom on the levels of SOD, CAT and GPx in the brain of control and experimental rats. 
Citation: Priyadharsini S, Manoharan J, Varadharajan D, Subramaniyan A (2015) Neuroprotective Effects of Pterois volitans Venom against Alcohol Induced Oxidative Dysfunction in Rats. J Environ Anal Toxicol 5: 306. doi:10.4172/2161-0525.1000306

Page 4 of 5
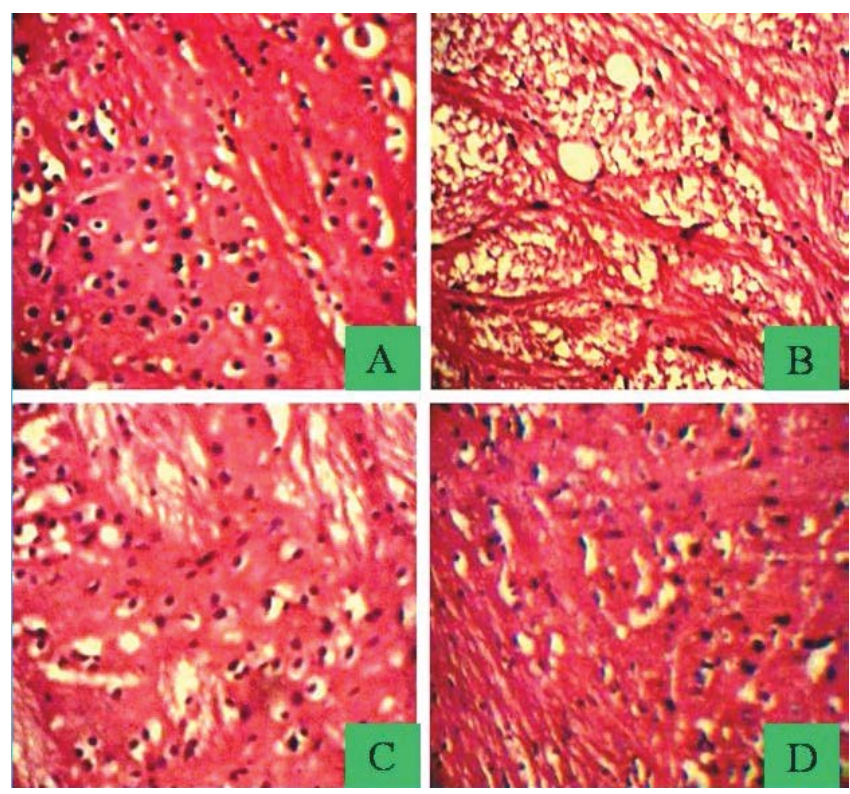

Figure 5: Histopathology of brain tissue of $(A)$ normal rat $(\times 10)$; $(B)$ Alcohol treated rat $(\times 10)$; (C) Rat pretreated with venom followed by alcohol administration $(\times 10)(D)$ Rat treated with venom alone $(\times 10)$.

status in the brain of control and experimental rats were presented in Table 2. A significant $(\mathrm{P}<0.05)$ decrease in the activities of SOD, CAT and GPx were observed in alcohol intoxicated rats when compared with control rats. Treatment with venom in alcohol intoxicated rats showed a significant $(\mathrm{P}<0.05)$ increase in the activities of antioxidant enzymes in the brain when compared with alcohol intoxicated rats.

\section{Histopathological changes in brain}

Figure 5 illustrate the histopathological structure of brain tissue of control and experimental animals. (B) Alcohol intoxicated rats exhibited marked gliosis, nuclear pycnosis spongiform necrosis and lymphocytic inflammatory infiltrates as against normal architecture shown by the brain of vehicle (A). There is no significant histo architechture of brain tissue in venom treated (D) rats when compared with control rats. (C) Treatment with venom prior to the alcohol intoxication reduced the incidence of these pathological changes in the brain tissue and showed almost normal architecture similar to those of the untreated control.

\section{Discussion}

The current study demonstrated that fish $P$. volitans venom could mitigate memory impairment in animal model of alcoholism. Brain has been reported to be susceptible to lipid peroxidation, since it consumes a large amount of oxygen and is rich in polyunsaturated fatty acids, which are especially prone to reactive oxygen species (ROS) injury [27]. Increasing evidences suggested that, excessive production of free radicals in brain and the imbalance between oxidative species and antioxidant defences are related to the pathogenesis of neurodegenerative diseases. Oxidative stress is a possible mechanism for the alcohol-induced brain damage for many reasons. The brain processes large amounts of $\mathrm{O}_{2}$ in relatively small mass, and has a high content of substrates available for oxidation (i.e. polyunsaturated fatty acids and catecholamines) in conjunction with low antioxidant activities, making it extremely susceptible to oxidative damage. Alcohol treated rats showed the increased levels of TBARS in this present study. Administration of venom in alcohol intoxicated rats significantly attenuated the increased levels of TBARS with concomitant improvement in the levels of brain enzymatic and non-enzymatic antioxidant defences.

Since the brain AChE activity is an important regulator of the behavioural processes, the decreased level of AChE in brain might be one of the indicators for alcohol induced toxic manifestations. Administration of venom in alcohol intoxicated rats restored the activity of AChE in brain. An important aspect of venom's role in neuroprotection is by the attenuation of radical formation through its acetylcholine (Ach) or a cholinomimetic compound present in the fish venom. Accumulating lines of evidence had suggested that the availability of ACh lead to increased levels of acetylcholinesterase (AChE) activity [28]. Several studies have examined the role of oxidative stress in developmental alcohol-mediated enzymatic and non-enzymatic depletion, possibly via the formation of free radicals [29-31]. GSH is the most abundant non-protein thiol that maintains the cellular redox status and providing first line of antioxidant protection against oxidative stress in brain. Thiols are potent cheaters capable of mobilizing even intracellularly bound alcohol and also provide an antioxidant defence function by removing alcohol from the site of deleterious oxidant reactions. The diminished levels of GSH and TSH in alcohol intoxication could be due to increased utilization to overwhelm the production of free radicals by alcohol and subsequent lipid peroxidation in brain. The activities of SOD, CAT and GPx, which were further decreased in the presence of Alcohol. SOD, CAT and GPx constitute the principal component of enzymatic antioxidant system against oxidative stress. SOD dismutates $\mathrm{O}_{2}$ to $\mathrm{H}_{2} \mathrm{O}_{2}$, which is removed by GPx and catalase. Moreover, the active compound of lionfish venom (cholinomimetic) may contribute to improve the tissue thiol pools, which could be associated with a reduction in alcohol induced oxidative threat and increased antioxidant status in venom administrated alcohol-treated rats.

\section{Acknowledgements}

The authors are thankful to the Department of Zoology, Annamalai University to provide for facilities and encouragement.

\section{References}

1. Lieber CS (1997) Role of oxidative stress and antioxidant therapy in alcoholic and nonalcoholic liver diseases. Adv Pharmacol 38: 601-628.

2. Wei H, Derson Y, Xiao S, Li L, Zhang Y (1999) Alcohol consumption and alcohol-related problems: Chinese experience from six area samples, 1994. Addiction 94: 1467-1476.

3. Diehl AM (2002) Liver disease in alcohol abusers: clinical perspective. Alcohol 27: 7-11.

4. Tuma DJ, Casey CA (2003) Dangerous byproducts of alcohol breakdownfocus on adducts. Alcohol Res Health 27: 285-290.

5. Sheweita SA, El-Gabar MA, Bastawy M (2001) Carbon Tetrachloride-Induced Changes in the Activity of Phase II Drug Metabolizing Enzyme in the liver of Male rats: Role of Antioxidants. Toxicology 165: 217-224.

6. Kreger AS, Molgó J, Comella JX, Hansson B, Thesleff S (1993) Effects of stonefish (Synanceia trachynis) venom on murine and frog neuromuscular junctions. Toxicon 31: 307-317.

7. Kulbicki M, Beets J, Chapanet P, Cure K, Darling E, et al. (2012) Distribution of Indo-Pacific lionfishes Pterois spp. in their native ranges: implications for the Atlantic invasion. Mar Ecol Prog Ser 446: 189-205.

8. Williamson JA, Fenner PJ, Burnett JW, Rifkin JF (1996) Venomous \& Poisonous Marine Creatures: A Medical and Biological Handbook. Sydney: University of New South Wales Press. Pp. 73.

9. Church JE, Hodgson WC (2002) The pharmacological activity of fish venoms Toxicon 40: 1083-1093.

10. Cohen AS, Olek AJ (1989) An extract of lionfish (Pterois volitans) spine tissue contains acetylcholine and a toxin that affects neuromuscular transmission. 
Citation: Priyadharsini S, Manoharan J, Varadharajan D, Subramaniyan A (2015) Neuroprotective Effects of Pterois volitans Venom against Alcohol Induced Oxidative Dysfunction in Rats. J Environ Anal Toxicol 5: 306. doi:10.4172/2161-0525.1000306

Toxicon 27: 1367-1376

11. Church JE, Hodgson WC (2000) Similarities in the Pharmacological Activity of Venoms from Australian Fish. Proc Aust Soc Clin Exp Pharmacol Toxicol 8: 15.

12. Klaassen CD, Watkins JB (1999) Casarett and Doull's Toxicology: The Basic Science of Poisons, McGraw-Hill, New York.

13. Haavaldsen R, Fonnum F (1963) Weever venom. Nature 199: 286-287.

14. Russell FE, Harreveld A (1954) Cardiovascular effects of the venom of the round stingray, Urobatis halleri. Arch Int Physiol Biochim 62: 322-333.

15. Garnier P, Grosclaude JM, Goudey-Perrière F, Gervat V, Gayral P, et al. (1996) Presence of norepinephrine and other biogenic amines in stonefish venom. J Chromatogr B Biomed Appl 685: 364-369.

16. Khoo HE, Yuen R, Poh CH, Tan CH (1992) Biological activities of Synanceja horrida (stonefish) venom. Nat Toxins 1: 54-60.

17. Rodrigues RJ (1972) Pharmacology of South American freshwater stingray venom (Potamotrygon motoro). Trans N Y Acad Sci 34: 677-686.

18. Lowry OH, Rosebrough NJ, Farr AL, Randall RJ (1951) Protein measurement with the Folin phenol reagent. J Biol Chem 193: 265-275.

19. Williamson JA (1995) Clinical Toxicology of Venomous Scorpaenidae and other selected Fish stings. In: Meier J, White J (eds.) Clini Toxicol Ani Venoms Poisons CRC Press, Florida. Pp 142-158.

20. Ellman GL, Courtney KD, Andres V Jr, Feather-stone RM (1961) A new and rapid colorimetric determination of acetylcholinesterase activity. Biochem Pharmacol 7: 88-95.
21. Niehaus WG Jr, Samuelsson B (1968) Formation of malonaldehyde from phospholipid arachidonate during microsomal lipid peroxidation. Eur J Biochem 6: 126-130.

22. Moron MS, Depierre JW, Mannervik B (1979) Levels of glutathione, glutathione reductase and glutathione S-transferase activities in rat lung and liver. Biochim Biophys Acta 582: 67-78.

23. Ellman GL (1959) Tissue sulfhydryl groups. Arch Biochem Biophys 82: 70-77.

24. Kakkar P, Das B, Viswanathan PN (1984) A modified spectrophotometric assay of superoxide dismutase. Indian J Biochem Biophys 21: 130-132.

25. Sinha AK (1972) Colorimetric assay of catalase. Anal Biochem 47: 389-394.

26. Rotruck JT, Pope AL, Ganther HE, Swanson AB, Hafeman DG, et al. (1973) Selenium: biochemical role as a component of glutathione peroxidase. Science 179: 588-590.

27. Montoliu C, Vallés S, Renau-Piqueras J, Guerri C (1994) Ethanol-induced oxygen radical formation and lipid peroxidation in rat brain: effect of chronic alcohol consumption. J Neurochem 63: 1855-1862.

28. Phachonpai W, Wattanathorn J, Tong-un T, Thipkaew C, Uabundit N, et al (2012) Assessment of Neuropharmacological Activities of Terminalia Chebula in Rats. American J Pharmacol Toxicol 7: 41-48.

29. Knecht KT, Bradford BU, Mason RP, Thurman RG (1990) In vivo formation of a free radical metabolite of ethanol. Mol Pharmacol 38: 26-30.

30. Lloyd RV, Hanna PM, Mason RP (1997) The origin of the hydroxyl radical oxygen in the Fenton reaction. Free Radic Biol Med 22: 885-888.

31. McCord JM (2000) The evolution of free radicals and oxidative stress. Am J Med 108: 652-659. 